\title{
"Nenhum passo attrás": algumas reflexões em torno da redução da maioridade penal
}

\author{
"No step behind": some reflections on reducing the criminal
}

\author{
Bruna Cristina Silva Oliveira \\ Assistente social do Centro de Referência de Assistência Social do Município de Major \\ Sales-RN, graduada em Serviço Social pela Universidade do Estado do Rio Grande do \\ Norte (UERN), Mossoró, RN, Brasil. brunacristina-ms@outlook.com
}

\begin{abstract}
Resumo: Apesar das conquistas preconizadas pelo Estatuto da Criança e do Adolescente, presenciamos, por parte de setores conservadores, um forte apelo em torno da redução da idade penal para dezesseis anos. Dessa forma, o presente artigo tem como objetivo tratar sobre a ineficiência da redução da maioridade penal, uma vez que concluímos que tal proposta não compreende os adolescentes dentro das cadeias de desigualdade social na qual estão inseridos, limitando-se a culpabilizar o sujeito por uma questão que, mais do que individual, é estrutural e social.
\end{abstract}

Palavras-chave: Adolescente em conflito com a lei. Redução da maioridade penal. Sistema prisional. Violência.
Abstract: Despite the achievements of the Statute of the Child and the adolescent, we have witnessed, on the part of conservative sectors, a strong appeal about the reduction of the penal age for the 16 years. Thus, this article aims to deal with the inefficiency of the reduction of the criminal majority, since, we conclude that this proposal does not understand the adolescents within the social inequality chains in which they are inserted, being limited to blaming the individual for a question that is more than individual and structural and social.

Keywords: Adolescent in conflict with the law. Reduction of the penal age. Prison system. Violence.

\section{Introdução}

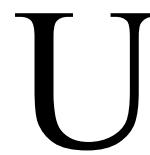

T $\mathrm{m}$ dos assuntos mais debatidos e polêmicos na atualidade brasileira se refere à redução da maioridade penal, que se materializa, entre outras emendas, no Projeto de Emenda Constitucional (PEC) n ${ }^{\circ} 171$, ao estabelecer a inimputabilidade para os menores de dezesseis anos. Essa proposta burguesa ganha, cada vez mais, adesão da classe trabalhadora, já que é perpassada por uma ideologia extremamente falaciosa, ilusória, 
sentimentalista e alienadora. O conteúdo da PEC $n^{\circ}$ 171/93 nega de forma clara todos os direitos conquistados arduamente pela sociedade brasileira no que se refere à proteção da criança e do adolescente, bem como desconsidera todos os fatores socioeconômicos que contribuem para a violência e a criminalidade, legitimando um Estado punitivo em detrimento de um Estado social.

Mascarada pela ideia de segurança pública e extirpação da violência, o que os defensores da redução da maioridade penal buscam, na verdade, é retirar do meio social todos os adolescentes que são improdutivos e que colocam em risco a ordem social e a harmonia entre as classes. Ao mesmo tempo, não se empenham em aumentar as penas dos nossos "representantes" políticos, que corriqueiramente roubam os cofres públicos e desmontam os direitos sociais.

Como sabem que se essa proposta for aprovada ela se destinará apenas ao pobre, negro e da periferia, incentivam a espetacularização dos atos infracionais cometidos por adolescentes, tendo a mídia como principal meio. Logo, objetivam fazer com que a população clame por medidas mais duras e punitivas para esses sujeitos e, assim, reduza o fenômeno da violência a uma questão individual, desconsiderando as amplas e complexas teias da desigualdade social.

\section{Violência é questão de políticas sociais, e não de algemas}

A violência é um fenômeno que está presente na sociedade desde os tempos mais remotos. Contudo até hoje ainda existe uma grande dificuldade de defini-la e conceituá-la de uma maneira mais abrangente, pois ela é um fenômeno multifacetado que possui formas e sentidos diferentes, de acordo com cada momento histórico, com a cultura, religião, costumes ou sociedade no qual é produzida. Nesse sentido, podemos afirmar que a violência é produto que se gesta dentro das relações sociais, ou seja, não é um fenômeno isolado, mas se objetiva em um dado momento histórico com suas respectivas particularidades sociais, econômicas, culturais e políticas, estando presente em todas as classes sociais. 
Marcada pela desigualdade, uma vez que no fenômeno da violência há sempre a sobreposição de um sujeito, grupo ou instituição sobre outro, podemos ainda dizer que uma de suas características mais nítidas é a manifestação do poder, seja ele materializado por meio do uso da força física ou não, situação na qual o violentador domina o violentado e, por sua vez, insere este último em um processo de coisificação, violando os direitos fundamentais da pessoa humana. Dessa forma, segundo Chaui (1999) apud Silva (2004b, p. 61),

toda violência age contra a liberdade, contra a vontade e contra a espontaneidade do ser violentado, uma vez que brutaliza, coage, constrange e viola sua natureza, tratando seres racionais e sensíveis como objetos a serem manipulados pela intimidação, pelo medo e pelo terror. Isso sem dúvida expressa uma determinada forma de poder, embora possa não ser legitimada, em determinadas situações, pela maioria da sociedade.

Compreender a violência no mundo contemporâneo significa, antes de qualquer coisa, inseri-la no movimento de produção e reprodução do capitalismo, pois fora dessa dinâmica teremos apenas uma aproximação fenomênica sobre o tema e, portanto, não conseguiremos captar sua essência e totalidade.

Ressaltamos, porém, que

Isto não significa afirmar, em absoluto, que qualquer tipo de violência praticada nessa ordem social seja direta e mecanicamente coordenada e causada por ela (ainda que, em seu caráter intrinsecamente contraditório, o capitalismo construa e reconstrua, ao mesmo tempo, maravilhas e mazelas, ordem e caos), mas que hoje a violência é elaborada e operacionalizada nesse modelo societário, sob suas condições e, portanto, é influenciada por essa forma de organização social. (Silva, 2004a, p. 136)

Entender a violência a partir da ótica da objetividade não implica desconsiderar os elementos subjetivos que também fazem parte de tal fenômeno, até mesmo porque objetividade e subjetividade não são coisas opostas, mas inseparáveis e interdependentes. Assim, 
Não se trata, em absoluto, de excluir essas características [subjetividade], em nada desprezíveis para a explicação da violência, mas de explicá-las a partir de um complexo circuito que se produz e se reproduz, em uma dada sociedade, a partir de condições sócio-históricas específicas, objetivando-se, com maior ou menor intensidade, nas diferentes instâncias da sociedade. (Silva, 2004b, p. 136)

A história do Brasil sempre foi marcada pela dominação de uma classe sobre outra, assentando-se em estruturas hierarquizadas que privilegiam pequenos grupos elitizados e marginalizam e excluem a grande massa popular, o que intensifica e amplia a desigualdade social e o fenômeno da violência. O nosso país foi, e ainda é, um território que condensa nas suas relações sociais, econômicas e políticas extremo clientelismo e paternalismo, além de restringir a garantia dos direitos humanos somente para a burguesia, ficando as classes subalternas à mercê da "bondade" dos governantes e da caridade das igrejas, o que desencadeia o surgimento de duas realidades, pois, por um lado, há condições humanas e dignas para um pequeno grupo dominante e, por outro, há miséria e negação dos direitos elementares para a grande massa dominada. Isso deixa mais do que claro que a violência, no tecido social brasileiro, "sempre esteve costumeiramente enraizada, institucionalizada e positivamente valorizada" (Silva, 2004b, p. 61).

Do período da colonização até os dias atuais, o Brasil tem passado por diversas e intensas transformações políticas e sociais. Durante esse percurso, muitos sujeitos tentaram construir estratégias que amenizassem as expressões da questão social que se intensificavam no cenário brasileiro. Contudo, a resposta mais legítima para a situação de opressão e exploração pela qual passava a classe trabalhadora veio apenas com a promulgação da Constituição Federal em 1988 (CF88), fruto das reivindicações, lutas e resistência dessa classe.

Instaura-se, no nosso país, um Estado democrático de direito, que deveria prover os elementos necessários para a garantia da dignidade humana por meio da efetivação das políticas sociais que são "padrões e até mesmo respostas e formas de enfrentamento às expressões da questão social no 
capitalismo, cujo fundamento se encontra nas relações de exploração do capital sobre o trabalho" (Behring e Boschetti, 2006, p. 51). Em outras palavras, podemos conceituar, abstratamente, as políticas sociais como instrumentos que devem materializar os direitos preconizados pela CF88 e garantir uma condição de vida digna para todos os cidadãos, independentemente de cor, classe, etnia, gênero ou raça. No entanto, sabemos que na realidade concreta não é isso o que acontece.

Contudo, em 1990, instaura-se no Brasil a ideologia neoliberal, que estabelece um Estado que investe e incentiva o mercado, reduz os custos no âmbito social, destitui os direitos sociais e fortalece a lógica do capital. Segundo essa ideologia, "o problema estaria localizado no Estado e, por isso, seria necessário reformá-lo para novas requisições, corrigindo distorções e reduzindo custos sociais" (Behring e Boschetti, 2006, p. 152). Assim, a tendência geral tem sido a "de restrição e redução de direitos, sob o argumento da crise fiscal do Estado, transformando as políticas sociais em ações pontuais e compensatórias direcionadas para os efeitos mais perversos da crise" (Idem, p. 156).

Toda essa conjuntura que assola a realidade brasileira se reflete diretamente na vida dos adolescentes, principalmente os autores de atos infracionais, pois, antes de violentarem, eles são extremamente violentados pelo Estado, que não oferece condições para que tenham uma vida minimamente digna, contribuindo, assim, para sua inserção conflituosa nas relações sociais. A convivência cotidiana com a violência estrutural

tem gerado nas comunidades pobres um ambiente de enfado, desânimo e desespero, que na juventude ressoa como sensação de cerco social e raiva, o que se amplia com os maciços apelos midiáticos ao consumo como única condição para a dignidade social. (Behring e Boschetti, 2006, p. 188)

O capitalismo não foi capaz, intencionalmente, de criar estratégias que conseguissem propiciar um desenvolvimento social mais justo e igualitário. Ao contrário, impulsionou a concentração de renda, a marginalização, a 
discriminação, a exploração e, consequentemente, a violência. Gera, assim, vários problemas societários que, dentro de um sistema de produção marcado pelo individualismo, passam a ser compreendidos como escolhas e fracassos pessoais, pois desconsidera os inúmeros determinantes macroeconômicos e objetivos que interferem de forma mais rigorosa nas ações aparentemente individuais.

Destarte, se por um lado a sociedade legitima a violência sofrida pelos adolescentes e, por outro, condena a praticada pelos mesmos, ela cria, no mínimo, um expressivo cenário de injustiça. Porém não era de se esperar o contrário dessa burguesia impiedosa, tendo em vista que legitimar a violência sofrida pelos adolescentes e condenar a praticada pelos mesmos significa atender a seus interesses de consolidar a falsa harmonia entre as classes sociais, bem como de diminuir os gastos com a classe trabalhadora, levando-os também a uma compreensão fatalista da realidade posta.

Na busca da sobreposição de um Estado penal em relação a um Estado social criam-se demasiados mitos sobre a adolescência em conflito com a lei. Entre eles destacamos a periculosidade e a impunidade dos adolescentes. A mídia, enquanto instrumento a serviço dos objetivos da classe dominante, propaga a falaciosa ideia de que "cada vez mais tem um número maior de infrações cometidas por adolescentes, que tais crimes são em maior volume que os cometidos por adultos e que estes atos infracionais são revestidos de grande violência" (Costa, 2005, p. 75). Entretanto, os dados mensurados pelo Ipea (2015) mostram outra realidade. Dos tipos de delitos praticados por adolescentes em cumprimento de medida, $39 \%$ são por roubo, $23 \%$ tráfico de drogas, e apenas 12,7\% são crimes contra a vida.

Pensar na contenção da violência é, antes de qualquer coisa, lutar pela efetivação dos direitos e das políticas sociais garantidos legalmente, pois somente "um Estado social forte, em proporções que nunca chegaram a fazer parte de nossa realidade, teria possibilidade de reverter à trajetória da violência em que se vê inserida nossa juventude" (Costa, 2005, p. 81).

Não é a redução da maioridade penal que vai diminuir a violência, mas, principalmente, entre outros fatores — uma vez que a violência é um 
fenômeno complexo que não está relacionado apenas às questões materiais e objetivas, mas também às pautas subjetivas e biológicas - , o fortalecimento de um Estado que garanta políticas sociais que propiciem condições de vida digna e humana para a população de forma igualitária, mediante o combate à desigualdade social, a exploração, a concentração de renda e a negação dos direitos que nos fazem homens e mulheres protagonistas da nossa história.

Dissemina-se a ideia de que o adolescente é o potencial gerador da violência. Porém os dados mostram que, contraditoriamente, os adolescentes são as maiores vítimas da violência no Brasil. Segundo o Mapa da Violência (Waiselfisz, 2015) a principal causa externa que leva adolescentes a óbito é o homicídio, representando em torno de $6,7 \%$ do total de mortes aos doze anos de idade; $14,0 \%$ aos treze; $25,1 \%$ aos catorze e assim por diante, até alcançar seu pico de participação aos dezessete anos de idade, quando atinge a marca de $48,2 \%$ na participação da mortalidade. De acordo com a passagem da infância para a adolescência, o total de óbitos por causas naturais vai diminuindo e os por causas externas vai aumentando, estando o homicídio como o principal motivador da morte dos jovens, na sua maioria negros e pobres. Entre as mortes por causas externas, apresentam especial incidência os homicídios, que ceifaram a vida de 3.749 jovens. Isto representa $46 \%$ do total de mortes ocorridas nessa faixa, quase a metade do total de mortes.

Dessa forma, reduzir a maioridade penal significa desconsiderar que a violência, em especial a relacionada ao crime, está diretamente articulada com a negação de direitos vivenciada pela maior parte da população, assim como também significa combater os fatores que a gestam de forma errônea, pois se a violência sofre determinações do contexto social e precário no qual estamos inseridos, não é a criação de prisões que vai resolvê-la, mas a implementação de políticas sociais universais. Portanto, "não é a revisão do Estatuto da Criança e do Adolescente ou a redução da inimputabilidade penal que vão diminuir a violência, mas a mudança das relações sociais e das condições de vida da população" (Faleiros, 2004, p. 93). 


\section{A falência do sistema prisional brasileiro}

Desde o seu surgimento, as prisões sempre se configuraram como espaços de repressão, opressão, violência e negação da dignidade humana, apesar de, ao longo da história, ter se apresentado de diferentes formas.

Na realidade brasileira, a política reinante é de sobreposição do Estado penal sobre o social, de higienização social e criminalização da pobreza, transformando as instituições penais em espaços com cor e classe social. Não se poderia esperar o contrário, pois, desde sua gênese, as prisões foram criadas para os que se encontram em posição de submissão, que colocam em risco a harmonia entre as classes sociais e que prejudicam os interesses da classe dominante.

Dessa forma, ao ser encoberta pela falaciosa ideia de espaço democrático e cidadão que proporciona a reconstrução moral e a ressocialização dos sujeitos que nela estão inseridos, a prisão torna-se o "pior pesadelo" dos apenados. Isto porque o sistema prisional no Brasil surge com o objetivo de encarcerar os pobres e aqueles que se rebelam contra as imposições do capitalismo, sendo, portanto, espaços ausentes de princípios humanitários.

As prisões, que deveriam ser locais de ressocialização, na conjuntura de precarização das políticas sociais e desresponsabilização do Estado com a garantia dos direitos humanos, acabam se tornando uma fábrica de violência, pois, ao lhe serem negados os direitos mais elementares, os apenados criam suas próprias regras, fazendo imperar, dentro dos presídios, a lei do mais forte. Isso impossibilita a efetivação de um processo de reeducação social, uma vez que esses detentos não conseguem refletir sobre a transgressão cometida, bem como encontrar outros caminhos de sobrevivência além do crime.

Contudo, embora o número de prisões tenha aumentado a violência não tem diminuído. A realidade hoje é de instituições de privação de liberdade totalmente superlotadas e ausentes de qualquer princípio de democracia, cidadania e dignidade humana, o que acarreta um grande número de reincidência no crime, pois, diante das estruturas defasadas dos presídios, não são oferecidos aos egressos recursos para construir uma nova identidade. 
Nesse sentido, a prisão transforma os egressos, só que em pessoas piores, uma vez que o que faz parte da realidade dos estabelecimentos prisionais são as desassistências jurídicas, psicológicas, sociais, materiais, de saúde, educacionais; a ociosidade; as torturas físicas, psicológicas, morais; os espancamentos; o abuso de poder por parte dos agentes do Estado, entre várias outras, ratificadas abaixo. (Ferreira, 2011, p. 519)

Existem diversas legislações, tanto nacionais como internacionais, que regulamentam o sistema prisional e preconizam várias garantias e direitos que deveriam existir nas instituições privativas de liberdade, desde o que se refere às questões materiais até os recursos humanos. Entretanto, apesar de o Brasil possuir um aparato jurídico avançado, a realidade concreta e material continua marcada pelo descaso, pela violência, pela tortura e pela desumanidade.

Dentro dos moldes da realidade brasileira, a população carcerária passa a ser vítima de inúmeras violações nos âmbitos físico, psicológico, sexual, moral e material, o que intensifica o processo de violação de sua integridade física, que se inicia desde seu nascimento com a omissão do Estado. Consequentemente, o cárcere se torna um espaço de produção e reprodução da violência. Então, como o aumento de prisões pode conter a violência?

Mediante o abandono e descompromisso governamental em relação aos estabelecimentos prisionais, "a assistência educacional e social não são efetivadas, e são elas a base da utópica construção de uma cidadania no sistema carcerário" (Ribeiro, 2014, p. 70). Logo, clama-se por penas mais duras e esquece-se de que a diminuição da violência não está relacionada ao arbítrio e à repressão, mas ao investimento e à materialização de políticas públicas sociais que proporcionem uma vida digna para os cidadãos e lhes dê condições de garantir suas necessidades. Contudo, é bem mais conveniente para o Estado, que é burguês, optar pela repressão e pelo controle social do que enfrentar a questão social de fato, pois isso significaria romper com a ordem social vigente.

Percebemos que o sistema prisional brasileiro não tem cumprido sua função legal, se materializando enquanto espaço de negação e violação de direitos, tanto por parte do Estado, como por parte dos próprios apenados. 
Isso demonstra a falência e a ineficiência do endurecimento das penas, uma vez que encarcerar significa tratar os problemas econômicos e sociais com políticas paliativas, ineficientes, focalistas e de cunho unicamente repressor, além também de devolver à sociedade sujeitos marcados por valores tão desumanos que, muitas vezes, eles são incapazes de sentir a dor do outro.

Construir um sistema prisional fundado na cidadania requer

efetivar direitos, investir em estrutura física, material e pedagógica nos estabelecimentos penais; será imprescindível a integralização das políticas públicas e de assistência aos sujeitos, antes, durante e depois do cárcere, bem como a participação da sociedade civil na sua reintegração; somente assim, poderemos vislumbrar a efetivação dos direitos dos apenados e a transformação das unidades prisionais brasileiras. (Ribeiro, 2014, p. 52)

O Estado é o maior causador da entrada de sujeitos no crime, haja vista que ao se desviar da sua função primária de provedor das condições necessárias para que os sujeitos tenham suas capacidades humanas e intelectuais potencializadas, ele gera um caos social, que se expressa por meio do desemprego, da vulnerabilidade social e da negação aos direitos sociais. Esses fatores influenciam diretamente no ingresso das classes subalternas ao mundo do crime, pois, como bem nos revela os dados levantados pelo Ministério da Justiça em parceria com o Departamento Penitenciário Nacional - Depen (Brasil, 2014), 67\% da população carcerária é de negros; 53\% não possuem o ensino fundamental completo; e $70 \%$ são condenados por crimes como tráfico de drogas, roubo, furto e receptação, isto é, que não ferem a vida. Assim, fica mais do que claro que se a maioria das infrações está relacionada à negação de direitos e ao consumo, não é o encarceramento que vai resolvê-la, e sim a mudança na estrutura das relações sociais, mediante a efetivação das políticas sociais e, posteriormente, instauração de uma nova forma de sociabilidade.

Se realmente a sociedade estiver preocupada com a ressocialização dos adolescentes autores de atos infracionais, seus agentes irão lutar contra o encarceramento desses sujeitos no regime privativo de liberdade comum, haja vista que as estruturas do sistema prisional brasileiro estão totalmente 
defasadas, distantes do que estabelecem os aparatos jurídicos que o regulamenta, não oferecendo nenhuma possibilidade de mudança de valores.

Por isso a defesa da redução da maioridade penal revela a busca pela legitimação dos interesses burgueses, uma vez que retira do Estado seu dever de contribuir na instauração de uma sociedade mais justa, cidadã e igualitária e, por conseguinte, o uso de um Estado penal para suprir a ausência do Estado social. Desta forma,

Oferecendo uma alternativa econômica, social, de saúde e educacional, estar-se-á atacando a raiz do problema e destruindo o círculo vicioso prisão-crime-prisão que aprisiona gerações; estar-se-á construindo outra cultura, não a da punição/prisão, mas a cultura do direito, da participação, da democracia e do exercício da cidadania. (Ferreira, 2011, p. 532)

Ser contrário ao encarceramento como a única forma de resolver os "problemas" causados por aqueles que se desviam das regras legitimadas não quer dizer que as prisões devam deixar de existir. Mas, significa compreender que elas devem ser usadas como último recurso, sendo necessário primeiro garantir condições dignas e humanas de sobrevivência para a população. E quando usadas, devem ser permeadas por valores humanos e assistência médica, social, jurídica e psicológica, para que os sujeitos inseridos no sistema prisional possam realmente viver um processo de reeducação que lhes possibilite reinserir-se nas relações sociais.

Só será possível resolver o problema da violência e da criminalidade quando os pensarmos à luz da luta de classes e da contradição do modo de produção capitalista. Fora dessa realidade, só conseguiremos construir estratégias paliativas e imediatistas. "Reforçamos a necessidade da construção de uma nova cultura menos repressiva e mais humana, menos coercitiva e mais democrática. Uma cultura em que o valor máximo seja a liberdade e o respeito ao outro" (Ferreira, 2011, p. 521).

Podemos, então, afirmar que reduzir a maioridade penal para dezesseis anos e encarcerar prematuramente adolescentes jamais vai resolver o fenômeno da violência, tampouco trazer segurança para a sociedade, pois, 
como bem mostramos, a finalidade da prisão não foi e nunca será recuperar homens e mulheres para que por meio de um processo de reeducação social possam se reinserir nas relações societárias.

Assim, responsabilizar os adolescentes por um problema que, mais do que pessoal, é social, é no mínimo injusto e injustificável. Em vez dessa atitude retrógrada, devemos reivindicar do Estado a materialização dos direitos conquistados pela classe trabalhadora.

\section{Conclusão}

A proposta de redução da maioridade penal apresenta-se como um tema bastante polêmico na sociedade brasileira, que se divide entre os conservadores que defendem essa proposta e os militantes dos direitos da criança e do adolescente e demais segmentos organizados da classe trabalhadora que defendem a permanência das medidas socioeducativas e a responsabilização do Estado para com a real materialização dessas.

Mascarada pela ideia de segurança pública e extirpação da violência, o que os defensores da redução da maioridade penal buscam, na verdade, é retirar do meio social todos os adolescentes que são improdutivos e que colocam em risco a ordem social e a harmonia entre as classes. De forma contraditória, não se empenham em aumentar as penas dos nossos "representantes" políticos, que corriqueiramente roubam os cofres públicos e os direitos sociais. Como sabem que se essa proposta for aprovada ela se destinará apenas ao pobre, negro e da periferia, incentiva-se a espetacularização dos atos infracionais cometidos por adolescentes, tendo a mídia como principal meio, fazendo com que a população clame por medidas mais duras e punitivas para esses sujeitos e, assim, reduza tal fenômeno a uma questão individual, desconsiderando as amplas e complexas teias da desigualdade social.

Compreendendo a violência como, entre outros fatores, uma expressão das relações sociais desiguais gestadas no seio da sociedade capitalista, fica claro que a mesma não é questão de algemas ou polícia, mas sim de políticas 
públicas capazes de redistribuir a concentração de riquezas e amenizar os níveis de desigualdade, pois entendemos que antes de se tornarem violadores, esses adolescentes são, desde seu nascimento, violentados pelo Estado, que não lhes garante o direito à saúde, educação, profissionalização, assistência, cultura, lazer, entre outros que são essenciais para uma vida minimamente digna.

Portanto, não é a revisão do Estatuto da Criança e do Adolescente ou a redução da idade penal que vai diminuir a violência, mas a mudança das relações sociais e das condições de vida da população.

Clamar pela redução também significa dar continuidade a ações, historicamente falidas, que combatem somente as consequências, e não as causas, uma vez que o sistema prisional tem demonstrado, desde sua origem, o fracasso e a falência de sua função de reduzir o índice de criminalidade e, portanto, de educar o preso para a convivência coletiva.

Marcado pela superlotação, insalubridade, violência e descaso público, o sistema prisional brasileiro é incapaz de proporcionar qualquer possibilidade de ressocialização, uma vez que as prisões são verdadeiros depósitos humanos e, por conseguinte, fábricas de violência. "Jogar" adolescentes dentro de presídios nada mais significa do que potencializar o fator negativo que os levou à autoria do ato infracional.

Dessa forma, a proposta da redução da maioridade penal, ao reatualizar a perspectiva punitiva e opressora dos códigos de menores, representa um retrocesso na garantia dos direitos conquistados tão arduamente pela classe trabalhadora. Por essa razão, não podemos permitir que ela seja aprovada, mas devemos nos inserir na luta em defesa dos direitos da criança e do adolescente, pois não são as medidas socioeducativas que não são eficientes. O Estado é que não dispõe dos recursos necessários para sua efetivação, tal como estabelece o ECA, uma vez que ao ser um aliado da burguesia, se desresponsabiliza da sua obrigação de investir na efetivação das políticas sociais e de garantir os direitos e o bem-estar da população.

Recebido em 20/4/2017 - Aprovado em 23/10/2017 


\section{Referências bibliográficas}

BEHRING, Elaine Rossetti; BOSCHETTI, Ivanete. Política social: fundamentos e história. São Paulo: Cortez, 2006. (Biblioteca básica de Serviço Social, v. 2).

BRASIL. Ministério da Justiça. Levantamento nacional de informações penitenciárias. Brasília: Depen, jun. 2014.

COSTA, Ana Paula Motta. Adolescência, violência e sociedade punitiva. Serviço Social \& Sociedade, São Paulo, ano 26, n. 83, p. 63-83, 2005.

FALEIROS, Vicente de Paula. Impunidade e Inimputabilidade. Serviço Social \& Sociedade, São Paulo, n. 77, p. 78-97, 2004.

FERREIRA, Angelita Rangel. Crime-prisão-liberdade-crime: o círculo perverso da reincidência no crime. Serviço Social \& Sociedade, São Paulo, n. 107, p. 509-534, jul./set. 2011.

IPEA. O adolescente em conflito com a lei e o debate sobre a redução da maioridade penal: esclarecimentos necessários. Brasília, jun. 2015. Disponível em: $<$ http://www. ipea.gov.br/portal/images/stories/PDFs/notatecnica_maioridade_penal $>$. Acesso em: 21 jan. 2016.

RIBEIRO, Ana Lígia Silva. Calabouços do século XXI: reflexões sobre o sistema prisional do estado do Rio Grande do Norte. 2014, 84 p. Monografia (Graduação Serviço Social). Universidade do Estado do Rio Grande do Norte. Faculdade de Serviço Social, Mossoró, 2014.

SILVA, José Fernando Siqueira da. Violência, Serviço Social e Formação Profissional. Serviço Social \& Sociedade, São Paulo, ano 25, n. 79, p. 133-147, 2004a. . “Justiceiros” e violência urbana. São Paulo: Cortez, 2004b.

WAISELFISZ, Julio Jacobo. Mapa da violência 2015. Faculdade Latino-Americana de Ciências Sociais - Flacso. Rio de Janeiro, 2015. Disponível em: <http://www. mapadaviolencia.org.br/pdf2015/mapaViolencia2015_adolescentes.pdf $>$. Acesso em: 21 jan. 2016. 